\title{
Influence of natural deposition plane orientation on oedometric consolidation behavior of three typical clays from southeast coast of China"
}

\author{
Qi-yin ZHU ${ }^{\dagger 1,2}$, Yin-fu JIN ${ }^{1,2}$, Zhen-yu YIN ${ }^{\dagger 1,2}$, Pierre-Yves HICHER ${ }^{2}$ \\ ('Department of Civil Engineering, Shanghai Jiao Tong University, Shanghai 200240, China) \\ ( ${ }^{2}$ LUNAM University, Ecole Centrale de Nantes, GeM UMR CNRS 6183, Nantes, France) \\ †E-mail: qiyin.zhu@gmail.com; zhenyu.yin@gmail.com \\ Received May 7, 2013; Revision accepted Oct. 14, 2013; Crosschecked Oct. 16, 2013
}

\begin{abstract}
The parameters obtained from oedometric consolidation tests are commonly used in the development of constitutive modeling and for engineering practice. This paper focuses on the influence of the natural deposition plane orientation on oedometric consolidation behavior of three natural clays from the southeast coast of China. Oedometer tests were conducted on intact specimens prepared by sampling at a series of angles relative to the natural deposition plane. For each specimen, yield stress, compressibility indexes, secondary compression, and permeability coefficients were determined. The influence of the sampling angle on these properties was investigated, revealing that yield stress, compression index, swelling index, creep index, ratio of secondary compression coefficient to compression index $\left(C_{\alpha \mathrm{e}} / C_{\mathrm{c}}\right)$ and permeability coefficient were all dependent to some extent on the sampling angle. These findings indicate the role of the anisotropy due to the natural deposition on the oedometric consolidation behavior.
\end{abstract}

Key words: Clay, Compressibility, Consolidation, Creep, Permeability, Natural deposition doi: 10.1631 jzus.A1300156

Document code: A

CLC number: TU4

\section{Introduction}

Natural clayey deposits are widely distributed in the coastal regions of southeast China. In general, these deposits show diverse ground characteristics due to variations in depositional environment. Moreover, their post-depositional geotechnical characteristics, such as stress history, leaching processes, and variations in excess pore water pressure, are very

\footnotetext{
$\ddagger$ Corresponding author

* Project supported by the National Natural Science Foundation of China (Nos. 41240024 and 41372285), the Shanghai Pujiang Talent Plan (No. 11PJ1405700), the Research Fund for the Doctoral Program of Higher Education of China (No. 20110073120012), and the European Project CREEP (No. PIAPP-GA-2011-286397)

(c) Zhejiang University and Springer-Verlag Berlin Heidelberg 2013
}

complex. These natural deposits are usually extremely soft and present considerable problems in civil engineering construction. Thus, the design and construction of projects built on these natural deposits require complete geotechnical knowledge of the natural clays therein to prevent excessive settlementdeformation and associated structural damage (Zhang, 2011). Presently, the parameters used for design and construction are usually determined from laboratory tests on clay samples that have been cut vertically. However, the mechanical behavior of natural clays cut at different angles from the deposition plane can strongly vary (Lade and Kirkgard, 2000; Shen et al., 2008; Yin and Chang, 2009a; 2009b; Yin et al., 2009; Huang and Liu, 2011). Therefore, the present design methods using the parameters measured from vertical clay samples may lack reliability and are likely to 
generate inaccurate predictions, resulting in engineering problems.

Parameters from oedometric consolidation tests are the most basic parameters commonly used in the development of elastoplastic or viscoplastic models and for engineering practice (Chen et al., 2007; Yin and Hicher, 2008; Li Y.Q. et al., 2008; Wang et al., 2008, 2011; 2012; Li J.Z. et al., 2009; Karstunen and Yin, 2010; Feng, 2010; Yin et al., 2010; 2011; Duan et al., 2012; Wang and Yin, 2012; Yin et al., 2013). For instance, the compression and swelling indexes, the secondary compression coefficient and the permeability are all oedometric properties that may potentially influence decisions prior to initiating civil engineering projects. For this reason, oedometric properties of clays have been widely investigated (e.g., Miao et al., 2008; Zeng et al., 2011; Li et al., 2012). However, these experimental studies have primarily been conducted on clay samples cut vertically, therefore having an angle with the natural deposition plane depending on its in situ orientation, and few have investigated the influence of the sampling angle relative to the natural deposition plane on oedometric parameters of clays.

In this study, we performed oedometer tests carried out on samples of three natural clays from Southeast China coastal regions sampled at various angles relative to the natural deposition plane. The effect of the sampling angle was experimentally quantified, and then used to study the oedometric consolidation behavior of clays, including compression, swelling, creep, and permeability properties. The implications of these findings for construction projects on clay deposits were discussed.

\section{Clay samples and test program}

\subsection{Sampling and physical properties of clays}

The clay samples, hereafter designated based on their origins, were taken from the Minhang District of
Shanghai, Liuheng Island at Zhoushan, and Puzhou at Wenzhou (Fig. 1). Some basic physical properties of the tested clays are summarized in Table 1, indicating significant silt content. Considering the percentages of silt and sand, we can describe Shanghai clay as silt clay and Zhoushan clay as slightly sandy. The Casagrande (1936)'s plasticity chart was used to classify the three clays; all are above the A-line and can therefore be considered as inorganic clays (Fig. 2).

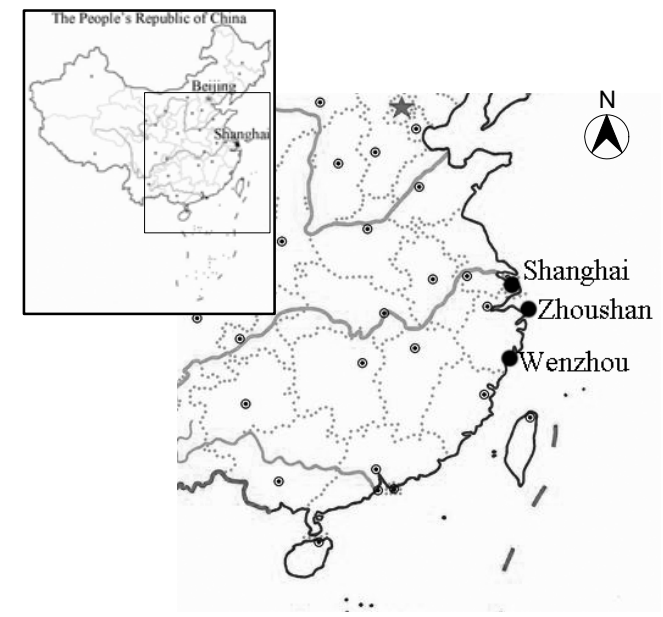

Fig. 1 Sample locations of tested clays

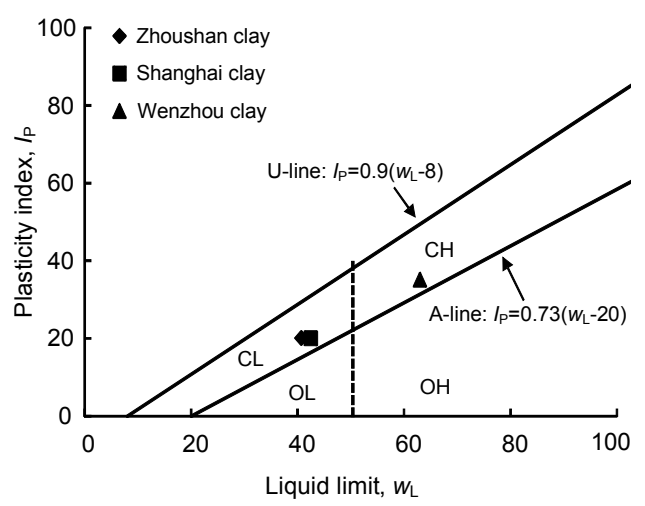

Fig. 2 Classification of clays by liquid limit and plasticity index

CL: low plastic inorganic clays, sandy, and silty clays; OL: low plastic inorganic or organic silty clays; $\mathrm{CH}$ : high plastic inorganic clays; $\mathrm{OH}$ : high plastic fine sandy and silty clays

Table 1 Physical properties of tested clays

\begin{tabular}{cccccccc}
\hline Clay & $\begin{array}{c}\text { Depth, } \\
h(\mathrm{~m})\end{array}$ & $\begin{array}{c}\text { Liquid limit, Plasticity index, } \\
w_{\mathrm{L}}\end{array}$ & $I_{\mathrm{P}}$ & $\begin{array}{c}\text { Initial void } \\
\text { ratio, } e_{0}\end{array}$ & $\begin{array}{c}\text { Percentage of } \\
\text { clay }(\%)\end{array}$ & $\begin{array}{c}\text { Percentage of } \\
\text { silt }(\%)\end{array}$ & $\begin{array}{c}\text { Percentage of } \\
\text { sand }(\%)\end{array}$ \\
\hline Shanghai & 12 & 42.5 & 20 & 1.08 & 26 & 72.4 & 1.6 \\
Zhoushan & 11 & 40.7 & 20 & 1.13 & 37 & 57.8 & 5.2 \\
Wenzhou & 8 & 63 & 35 & 1.98 & 44 & 54.8 & 1.2 \\
\hline
\end{tabular}


Shanghai clay and Zhoushan clay have low plasticity, while Wenzhou clay is high plastic clay.

The natural deposition has a significant influence on the anisotropy of clay structures. Fig. 3 shows the photos from scanning electronic microscopy (SEM) of three natural depositions in the vertical direction. These photos show clearly that the particles arrangement of natural clays is anisotropic. Using the software 'ImageJ', we analyzed the orientation of the clay particles on the vertical plane. An angular distribution plotted in a rose diagram gives the percentage of the particle surface area as a function of the particle orientation. The rose diagrams indicate a structural anisotropy with a preferential orientation of the particles towards the horizontal direction. A certain number of particles non-uniformly oriented in the $30^{\circ}-150^{\circ}$ quadrants can also be observed (Fig. 4).

(a)

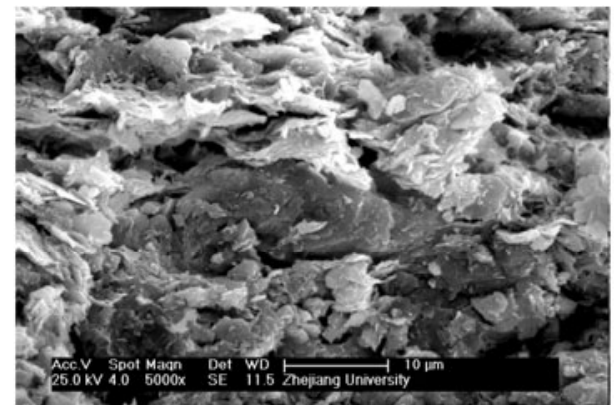

(b)

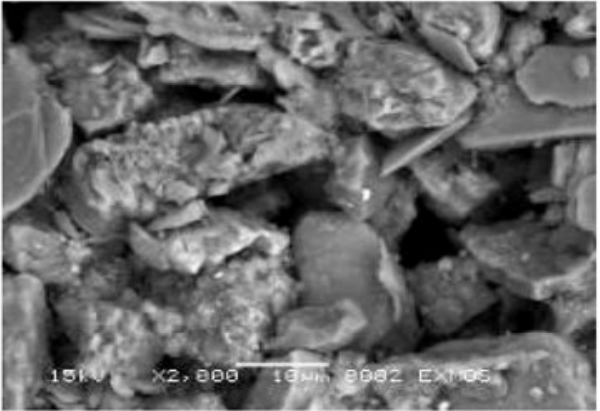

(c)

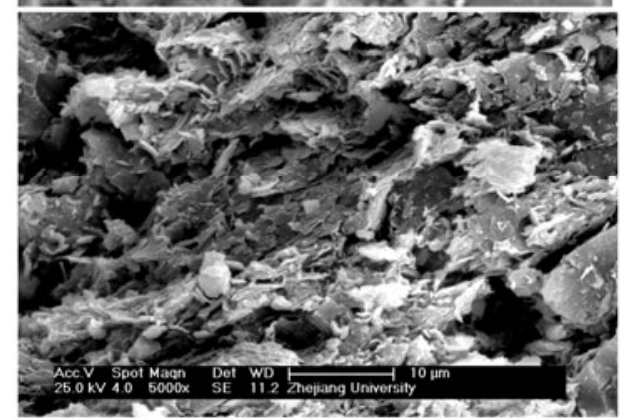

Fig. 3 SEM photos of natural depositions (on vertical plane): (a) Zhoushan clay; (b) Shanghai clay; (c) Wenzhou clay
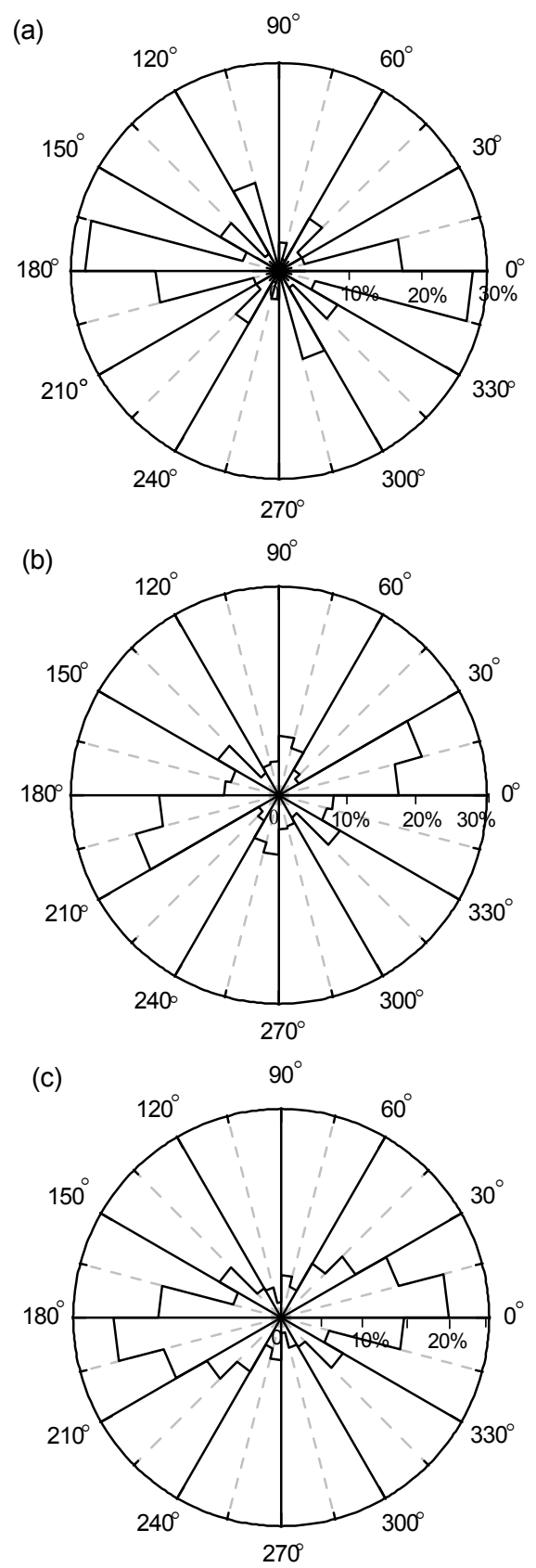

Fig. 4 Orientation of clay particles for natural depositions on vertical plane: (a) Zhoushan clay; (b) Shanghai clay; (c) Wenzhou clay

\subsection{Test program}

Fig. 5 illustrates a block of natural soil sampled from the field with the drive sampling techniques described by Clayton et al. (1982). The sedimentation, or natural deposition plane of the clay is assumed to mostly coincide with the in situ horizontal plane. To characterize the influence of the sampling angle on 
the consolidation behavior of clays, specimens prepared for oedometer testing were cut from the soil block at several different angles. The specimens of Zhoushan clay were sampled at angle $\theta$ of $0^{\circ}$ (i.e., perpendicular to the deposition plane), $30^{\circ}, 60^{\circ}$, and $90^{\circ}$ (i.e., parallel to the deposition plane), while specimens of Shanghai and Wenzhou clays were sampled at $\theta=0^{\circ}, 22^{\circ}, 45^{\circ}, 68^{\circ}$, and $90^{\circ}$.

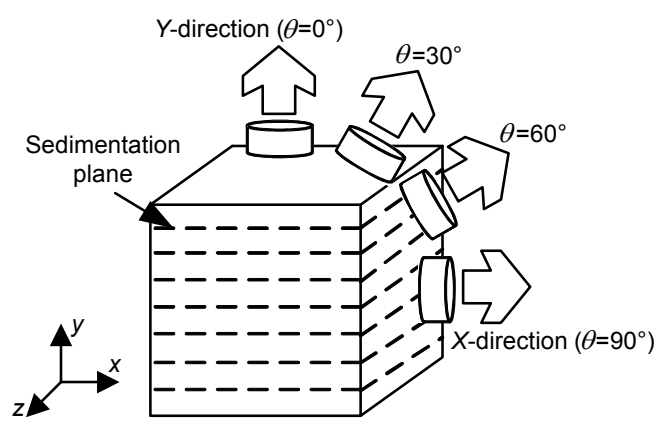

Fig. 5 Sample block of soil and sampling angle relative to natural deposition plane

Specimens were subjected to conventional oedometer tests according to Chinese Industry Standard (1999). All laboratory tests were conducted in a standard fixed-ring oedometer with $30 \mathrm{~cm}^{2}$ brass rings (diameter $d=61.8 \mathrm{~mm}$ ) and $20 \mathrm{~mm}$ in thickness. Each specimen was subjected to successive vertical stresses of $12.5,25,50,100,200,400,800,200,50,12.5,50$, 200,800 , and $1600 \mathrm{kPa}$, corresponding to a loading stage (12.5 to $800 \mathrm{kPa}$ ), an unloading stage ( 800 to $12.5 \mathrm{kPa})$ and a reloading stage $(12.5$ to $1600 \mathrm{kPa})$. Each stress step lasted $24 \mathrm{~h}$.

\section{Experimental results and analysis}

\subsection{Yield stress}

Fig. 6 shows the compression curves $\left(e-\log \sigma_{\mathrm{v}}^{\prime}\right)$ of specimens of the three clays with different sampling angles relative to the natural deposition plane. Differences among the four compression curves for Zhoushan clay were observed, with the compression curve of the $0^{\circ}$ specimen exhibiting the smallest change in void ratio and the compression curve of the $60^{\circ}$ specimen exhibiting the biggest change (Fig. 6a). In contrast, the five compression curves for Shanghai and Wenzhou clay specimens were highly similar, regardless of the sampling angle (Figs. $6 \mathrm{~b}$ and $6 \mathrm{c}$ ).
Based on these findings, the yield stress $\left(\sigma_{\mathrm{p} 0}^{\prime}\right)$ of each specimen was determined using the Casagrande method (Casagrande, 1936). Fig. 6d shows the change in yield stresses of Zhoushan, Shanghai and Wenzhou
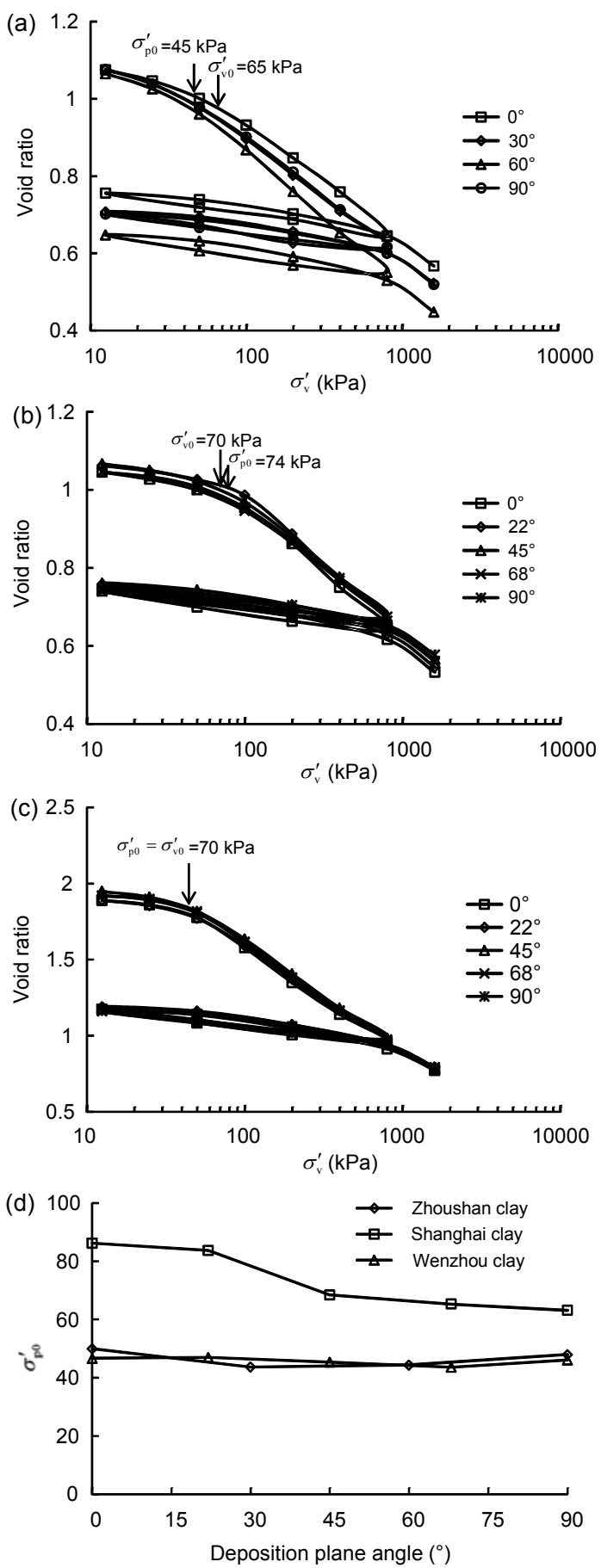

Fig. 6 Compression curves of samples from (a) Zhoushan clay, (b) Shanghai clay, (c) Wenzhou clay at different deposition planes; (d) yield stress versus sampling angle of the three clays 
clays functions relative to the sampling angles. It is clear that, for Shanghai clay, the value of $\sigma_{\mathrm{p} 0}^{\prime}$ is the biggest for the $0^{\circ}$ sample and gradually decreases as the sampling angle increases. The difference between the maximum and minimum values of $\sigma_{\mathrm{p} 0}^{\prime}$ for Shanghai clay is about $17 \mathrm{kPa}$. However, for Zhoushan and Wenzhou clays, $\sigma_{\mathrm{p} 0}^{\prime}$ was not strongly influenced by the sampling angle. Furthermore, comparing the average measured yield stress with the in situ vertical effective stress indicates that Zhoushan clay is underconsolidated, Shanghai clay is slightly overconsolidated $\left(\mathrm{OCR}=\sigma_{\mathrm{p} 0}^{\prime} / \sigma_{\mathrm{v} 0}^{\prime}=1.06\right)$ and Wenzhou clay is normally consolidated.

\subsection{Compressibility}

The compression $\left(C_{\mathrm{c}}\right)$ and swelling $\left(C_{\mathrm{s}}\right)$ indexes can be measured from the compression curves (Fig. 6). $C_{\mathrm{c}}$ is measured from the slope of the compression line between 200 and $800 \mathrm{kPa}$. Fig. 7a shows the change in $C_{\mathrm{c}}$ with the sampling angle for the three clays, along with the correlation coefficients for each linear regression, indicating overall that $C_{\mathrm{c}}$ varies very slightly with the sampling angle. Two values of $C_{\mathrm{s}}$ were measured: $C_{\mathrm{si}}$ related to the slope of the initial compression line between 12.5 and $25 \mathrm{kPa}$ fully induced by the natural clay deposition, and $C_{\text {sr }}$ related to the slope of the unloading and recompression lines additionally influenced by the first loading stage. Fig. $7 \mathrm{~b}$ shows the change in $C_{\text {si }}$ with the sampling angle for the three clays, putting into evidence the relatively large variations of these index values for each clay sample. Fig. $7 \mathrm{c}$ indicates that $C_{\mathrm{sr}}$ decreases slightly with the sampling angle.

\subsection{Secondary compression}

The change in void ratio occurring over one log cycle of time during the secondary compression phase is known as $C_{a \mathrm{e}}$ :

$$
C_{\mathrm{ae}}=\frac{\Delta e}{\Delta \log t}
$$

where $e$ is the void ratio and $t$ is the length of time since the end of the primary consolidation. $C_{\mathrm{ae}}$ is often used to assess the long-term deformation of clays, as it can account for the creep rate of soils (Yin et al., 2010). We therefore determined $C_{\alpha \mathrm{e}}$ for a variety of sampling angles for the three clays. Fig. 8 shows an example of $C_{\text {ae }}$ values determined from plots of $e$ vs. $\log t$ at each load increment for the $0^{\circ}$ specimen of Shanghai clay. The duration of the primary consolidation phase for Shanghai clay was
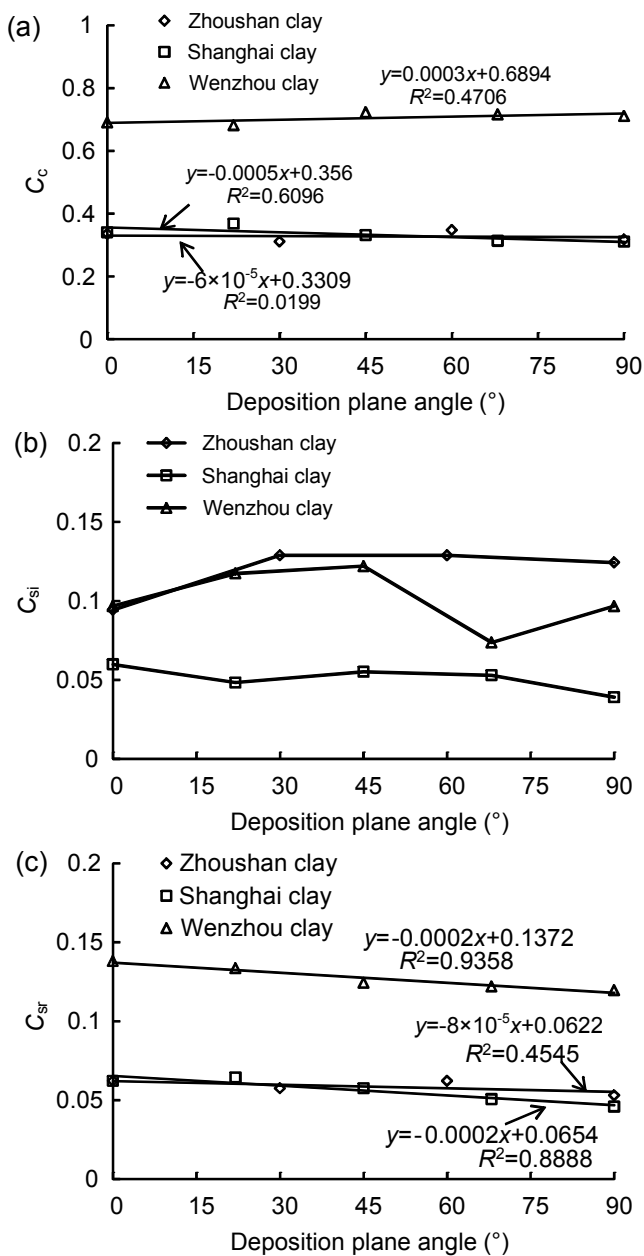

Fig. 7 Influence of sampling angle on (a) compression index, (b) swelling index for initial compression and (c) swelling index for unloading and recompression

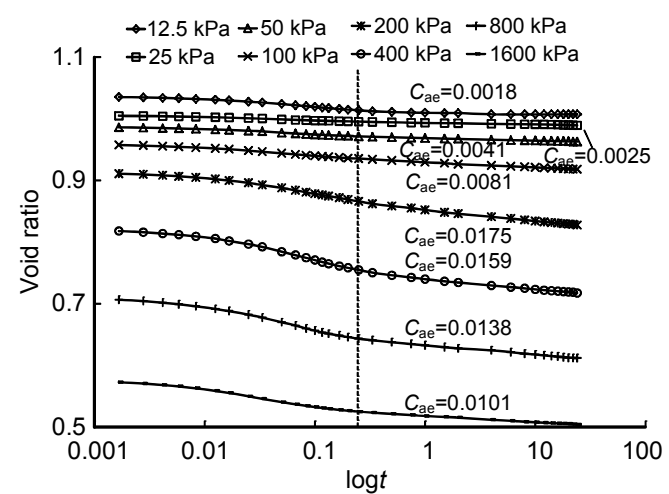

Fig. 8 Void ratio versus time for each load increment on Shanghai clay $\left(0^{\circ}\right.$ specimen $)$ 
determined to be about $15 \mathrm{~min}$, followed by the secondary consolidation. Based on the evolution of $e$ over time during the secondary consolidation stage, $C_{\alpha \mathrm{e}}$ was calculated for each load increment using Eq. (1). This approach was used to quantify $C_{\mathrm{ae}}$ for all specimens.

Fig. 9 shows changes in $C_{\text {ae }}$ for three clays sampled at different angles relative to the deposition plane, based on levels of vertical stress applied. For all three clays, $C_{a \mathrm{e}}$ increases with the increase in the consolidation stress regardless of the sampling angle and reaches a maximum at a stress about twice the preconsolidation pressure; thereafter, $C_{a \mathrm{e}}$ decreases irrespective of clay sample or sampling angle. This observation is consistent with previous studies (Mesri and Godlewski, 1977; Suneel et al., 2008) on various
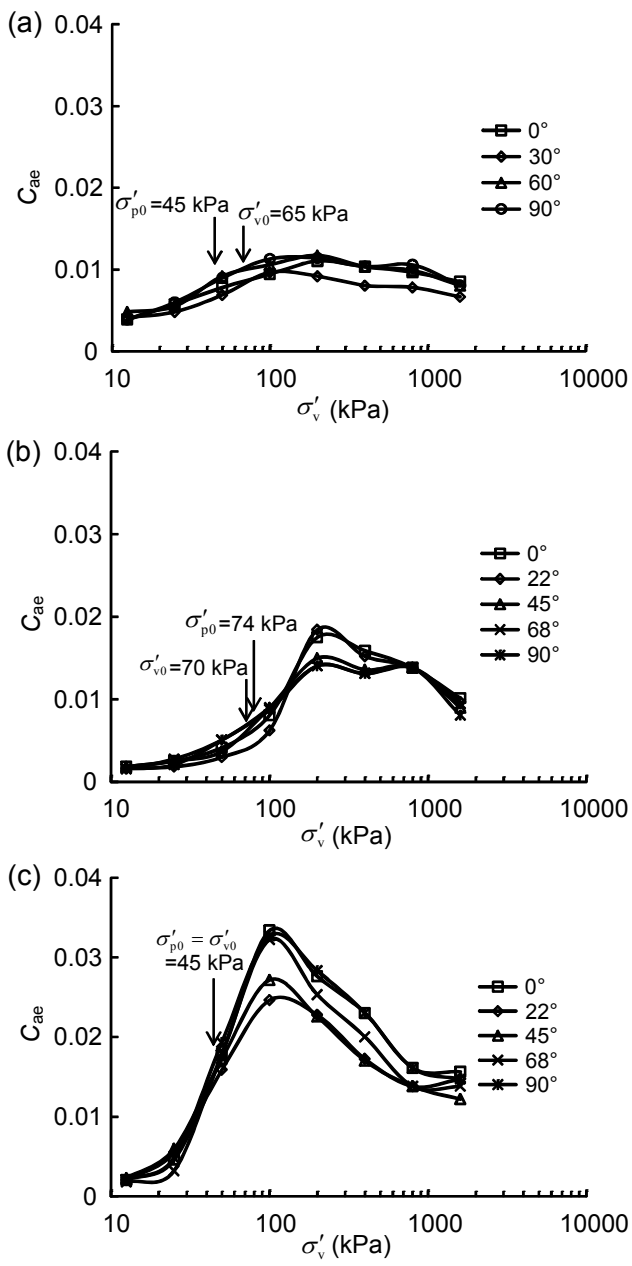

Fig. 9 Relationship between $C_{\alpha \mathrm{e}}$ and vertical stress for three clays sampled at different angles relative to their deposition planes: (a) Zhoushan clay, (b) Shanghai clay and (c) Wenzhou clay clays in the vertical direction.

Note that, for each clay, all samples have approximately the same initial void ratio, then the relationship between secondary compression $C_{\alpha e}$ and vertical stress can also be considered an expression of the relationship between $C_{\text {ae }}$ and void ratio upon completion of the test. We analyzed the relationship between $C_{\text {ae }}$ and the void ratio within the normally consolidated range of the clays, as shown in Fig. 10. $C_{a \mathrm{e}}$ appears to decrease roughly linearly with the void ratio in the double logarithm plane, which is in agreement with the evolution suggested by Yin $e t$ al. (2012). Meanwhile, the sampling angle relative to the natural deposition plane has a visible influence on the relationship between $C_{\alpha \mathrm{e}}$ and the void ratio that also depends on the clay. For Zhoushan clay, $C_{\alpha e}$ is the
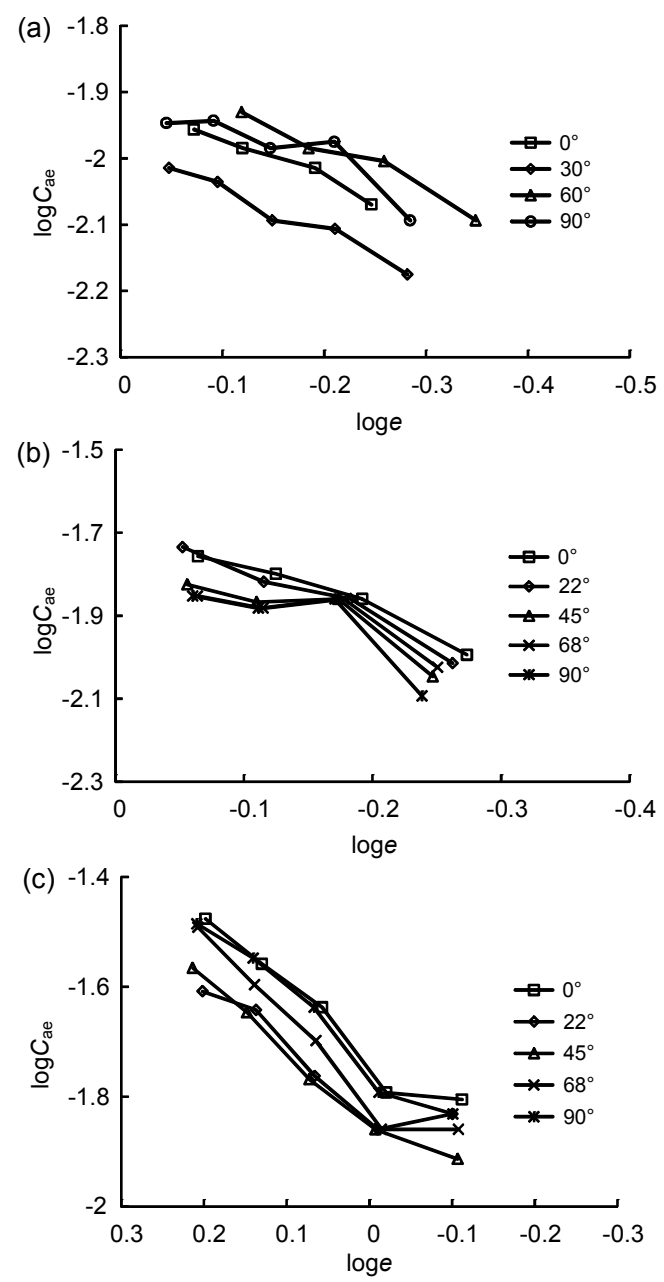

Fig. 10 Relationship between $C_{\alpha \mathrm{e}}$ and $e$ in the normally consolidated range for three clays with different sampling angles: (a) Zhoushan clay, (b) Shanghai clay, and (c) Wenzhou clay 
lowest for the $30^{\circ}$ specimen (Fig. 10a). However, for Shanghai clay, $C_{a \mathrm{e}}$ generally decreases with an increase in the sampling angle (Fig. 10b), and $C_{\mathrm{ae}}$ in Wenzhou clay increases with an increase in the sampling angle, apart from the $0^{\circ}$ specimen, which has the highest $C_{\text {ae }}$ for this clay (Fig. 10c).

For each clay we selected the maximum value of $C_{a e}$ and the value of $C_{a e}$ at the vertical stress of $1600 \mathrm{kPa}$ to represent the creep properties of the natural deposit from which the samples had been taken. Plotting the relationship between the maximum of $C_{\alpha e}$ and the sampling angle for each of the three clays shows that $C_{a \mathrm{e}}$ varies from 0.024 to 0.033 for the highly plastic Wenzhou clay (Fig. 11a), whereas $C_{\alpha \mathrm{e}}$ has a much smaller range for the low plasticity Shanghai clay $\left(C_{\alpha e}=0.014-0.018\right)$ and Zhoushan clay $\left(C_{\alpha e}=0.010-0.012\right)$. Notably, $C_{\alpha e}$ corresponding to a vertical stress of $1600 \mathrm{kPa}$ varies slightly with the deposition plane angle, likely because the soil microstructure was modified towards a similar state during loading up to a high stress level (Fig. 11b).

\section{$3.4 C_{a \mathrm{e}} / C_{\mathrm{c}}$ ratio}

Mesri and Godlewski (1977) summarized previously published $C_{\mathrm{ae}} / C_{\mathrm{c}}$ values for a number of
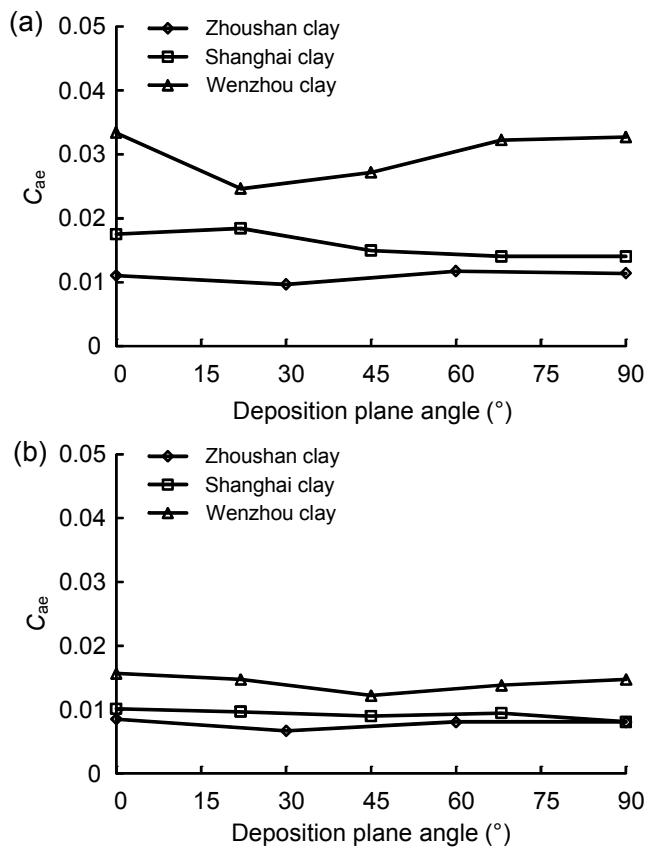

Fig. 11 Relationship between $C_{\alpha e}$ and deposition plane angle for three clays: (a) maximum $C_{\alpha \mathrm{e}}$; (b) $C_{\alpha \mathrm{e}}$ corresponding to a vertical stress of $1600 \mathrm{kPa}$ natural soils and found that this ratio ranged overall between 0.025-0.010. Mesri and Castro (1987) concluded that $C_{a e} / C_{\mathrm{c}}=0.04 \pm 0.01$ for most inorganic clays.

Fig. 12 presents the relationships between $C_{a \mathrm{e}}$ and $C_{\mathrm{c}}$ for all samples of the three clays. The results show that $C_{\mathrm{ae}} / C_{\mathrm{c}}$ ranges between 0.021 and 0.047 for
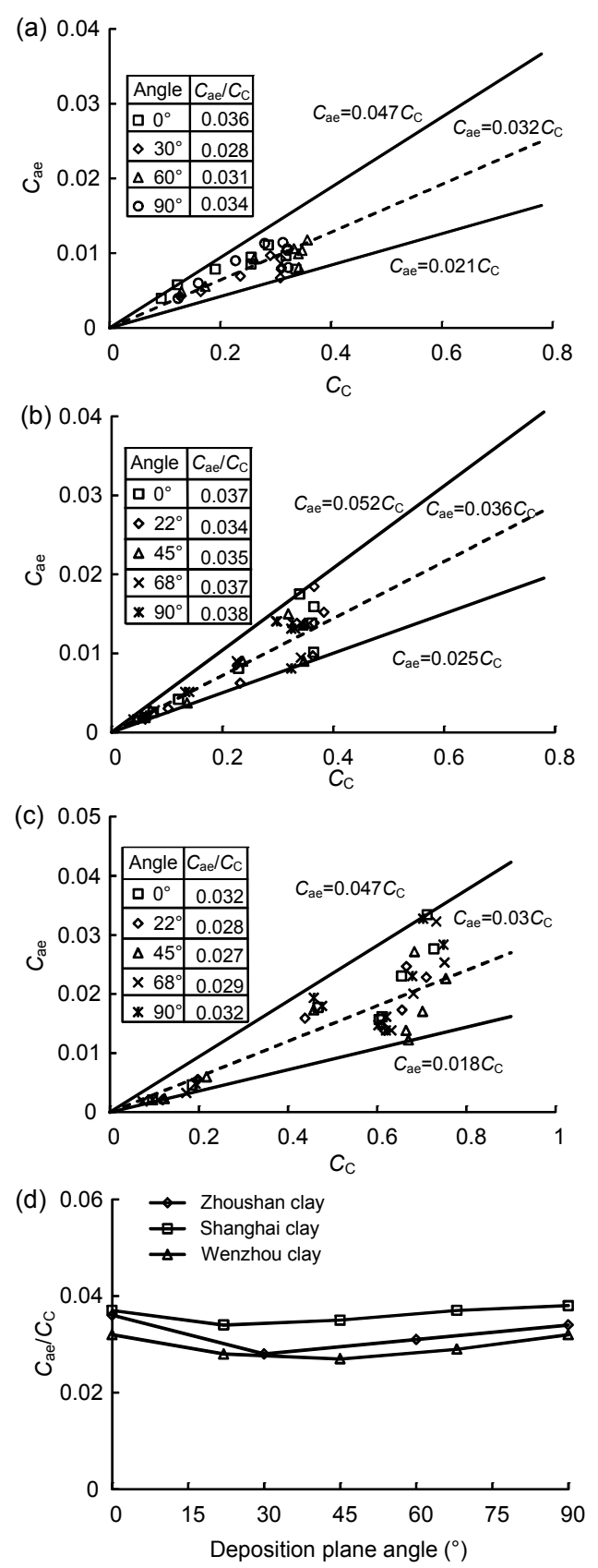

Fig. 12 Relationship between $C_{\alpha \mathrm{e}}$ and $C_{\mathrm{c}}$ for (a) Zhoushan, (b) Shanghai and (c) Wenzhou clays; and (d) average $C_{\alpha \mathrm{e}} / C_{\mathrm{c}}$ versus sampling angle for the three clays 
Zhoushan clay with an average value of 0.032 (Fig. 12a), between 0.025 and 0.052 for Shanghai clay with an average value of 0.036 (Fig. 12b), and between 0.018 and 0.047 for Wenzhou Clay with an average value of 0.03 (Fig. 12c). Tables inset within Fig. 12 list the average values of $C_{\mathrm{ac}} / C_{\mathrm{c}}$ for each of the clay sampling angles, and these data were used to plot the change in $C_{\mathrm{ae}} / C_{\mathrm{c}}$ as a function of the sampling angle (Fig. 12d). For the three clays, $C_{\mathrm{ae}} / C_{\mathrm{c}}$ first decreases, then increases as the sampling angle increased, with $0^{\circ}$ and $90^{\circ}$ samples generating the largest $C_{\mathrm{ae}} / C_{\mathrm{c}}$.

\subsection{Permeability}

The permeability coefficient $k$ is calculated by

$$
k=C_{\mathrm{v}} \gamma_{\mathrm{w}} m_{\mathrm{v}}
$$

where $C_{\mathrm{v}}$ is the coefficient of consolidation, $\gamma_{\mathrm{w}}$ is the unit weight of water and $m_{\mathrm{v}}$ is the coefficient of volume change. Since $C_{\mathrm{v}}$ and $m_{\mathrm{v}}$ varied with the sampling angle relative to the deposition plane, we calculated $C_{\mathrm{v}}$ from strain-time curves using the Terzaghi 1D consolidation theory.

Fig. 13 shows the $e$-logk relationships for Zhoushan, Shanghai and Wenzhou clays tested at different sampling angles relative to the natural deposition plane. The results show that the permeability coefficient $k$ decreases linearly with the decrease in the void ratio in a logarithmic plane for all specimens.

The initial permeability $k_{0}$ and the permeability index $C_{\mathrm{k}}$ are widely used in engineering calculations; hence, their changes in the sampling angle were used to evaluate the effects of the orientation of the natural deposition plane. Eq. (3) proposed by Berry and Poskitt (1972), i.e.,

$$
k=k_{0} \times 10^{\left(e-e_{0}\right) / C_{\mathrm{k}}},
$$

was used to determine the two permeability parameters $k_{0}$ and $C_{\mathrm{k}}$ based on $k, e$, and $e_{0}$. Given the initial void ratio $e_{0}$ and the linear regression between $e$ and $\log k$ for different sampling angles, the corresponding $k_{0}$ could be calculated. Meanwhile, $C_{\mathrm{k}}$ is the slope of the corresponding regression line, such as that plotted in Fig. 13a. We thereby determined $k_{0}$ and $C_{\mathrm{k}}$ for all samples. Fig. 14a shows that the sampling angle in- fluences $k_{0}$ in a positive, linear manner, with regression slope values of $0.0089,0.0074$, and 0.0050 for Zhoushan, Shanghai, and Wenzhou clays, respectively. The $k_{0}$ value for the vertical samples $\left(0^{\circ}\right)$ is the smallest, and the largest for the horizontal samples $\left(90^{\circ}\right)$ for all three clays. Previous results (O'Kelly, 2006) showed that the ratio of permeability values for horizontal relative to vertical samples is always larger than 1.0, and the present data are consistent with this finding. On the other hand, plotting $C_{\mathrm{k}}$ versus the sampling angle shows no significant influence of the latter on $C_{\mathrm{k}}$ (Fig. 14b).

\section{Discussion}

We found that the yield stress of Shanghai clay gradually decreases with the sampling angle, with
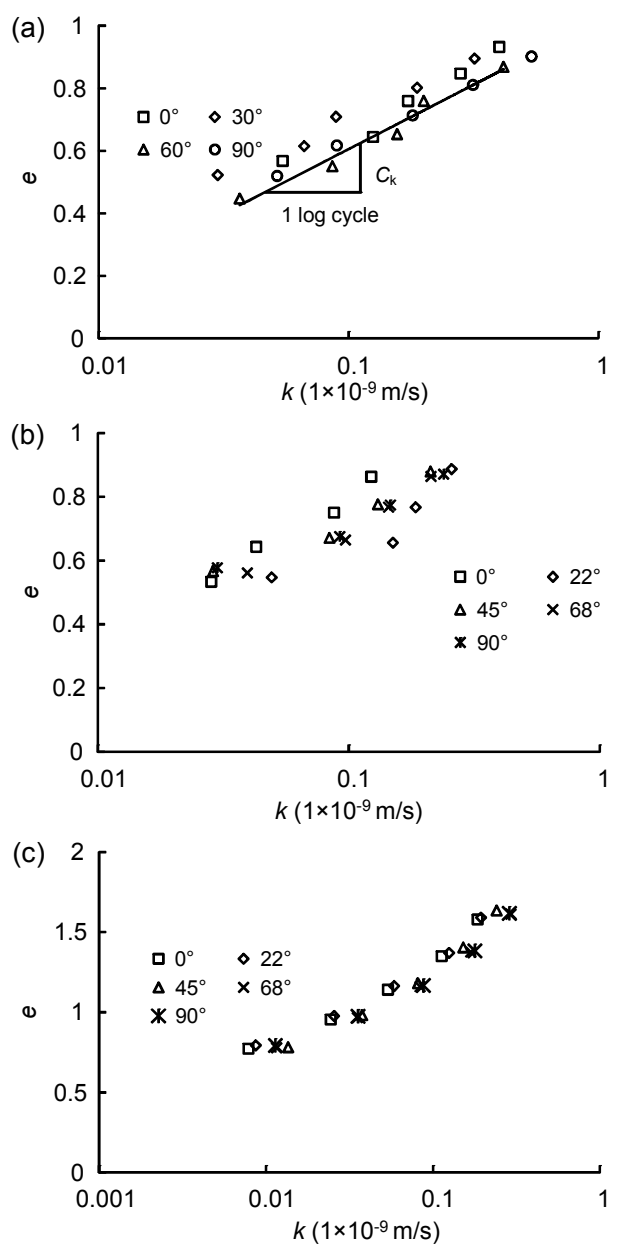

Fig. 13 Evolution of permeability with void ratio for clays from (a) Zhoushan, (b) Shanghai and (c) Wenzhou 

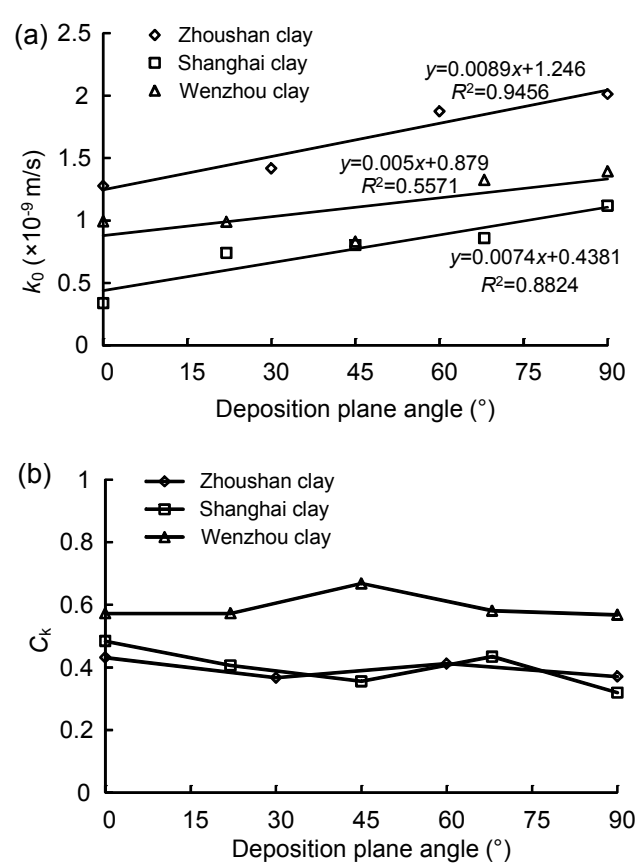

Fig. 14 Relationship between $k_{0}$ and sampling angle for three clays (a); Relationship between $C_{\mathrm{k}}$ and sampling angle for three clays (b)

about $17 \mathrm{kPa}$ difference between the maximum and minimum $\sigma_{\mathrm{p} 0}^{\prime}$. For Zhoushan and Wenzhou clays, however, $\sigma_{p 0}^{\prime}$ does not strongly vary. Furthermore, the highly plastic Wenzhou clay has a large range of $C_{a \mathrm{e}}$ that varies with the sampling angle, while the low plasticity Zhoushan and Shanghai clays have small ranges of $C_{a \mathrm{e}}$ values. Similar phenomena can be found for $C_{\mathrm{si}}$ and $C_{\mathrm{k}}$. Consequently, we can conclude that the anisotropic behavior is more obvious for clays of highly plasticity.

For isotropic compression, experimental evidence suggests that the initial anisotropy is erased by isotropic loading up to a pressure that is two or three times larger than the preconsolidation pressure (Leoni et al., 2008). If adopting this in an oedometer test, by assuming $K_{0}=0.5$ (friction angle $\phi=30^{\circ}$ ), the initial anisotropy will be removed after a vertical stress larger than 1.3 or 2 times preconsolidation pressure and the current conditions can be regarded as yielding. Fig. 11 shows the relationships between the maximum value of $C_{\text {ae }}$ (before yielding) and the value of $C_{a \mathrm{e}}$ at the vertical stress of $1600 \mathrm{kPa}$ (after yielding) and the sampling angle. The significant influence of initial anisotropy of clays before yielding on the anisotropic behavior of $C_{\text {ae }}$ can be observed. As the compression index $C_{\mathrm{c}}$ and swelling index $C_{\mathrm{sr}}$ was measured after yielding, and $C_{\mathrm{si}}$ was measured before yielding of clay, $C_{\mathrm{c}}$ and $C_{\mathrm{sr}}$ vary slightly with the sampling angle but not $\mathrm{C}_{\mathrm{si}}$ as shown in Fig. 7, also demonstrating the rationality of the above observation. In addition, the evolution of initial permeability $k_{0}$ with the sampling angle for three clays also gives positive supports (Fig. 14).

\section{Conclusions}

The effect of the orientation of the natural deposition plane on oedometric consolidation behavior of three natural clays from coastal regions of Southeast China was investigated by conducting a series of oedometer tests on specimens prepared by sampling a single clay block at a series of angles relative to the natural deposition plane. Conclusions can be drawn as follows.

1. The anisotropic behavior is more obvious for clays of highly plasticity. The highly plastic Wenzhou clay has a large range of $C_{\text {ae }}$ that varies with the sampling angle, while the low plasticity Zhoushan and Shanghai clays have small ranges of $C_{\text {ae }}$ values. Similar phenomena can be found for $C_{\mathrm{si}}$ and $C_{\mathrm{k}}$. The increase in $k_{0}$ with the sampling angle is smaller for high plasticity Wenzhou clay than for low plasticity Zhoushan and Shanghai clays.

2. The initial anisotropy of clays before yielding has a significant influence on the anisotropic behavior of clays. The maximum value of $C_{\alpha \mathrm{e}}$ varies very much and the value of $C_{a \mathrm{e}}$ corresponding to a vertical stress of $1600 \mathrm{kPa}$ varies slightly with the deposition plane angle for all three clays. The compression index $C_{\mathrm{c}}$ and swelling index $C_{\text {sr }}$ were found to vary slightly with the sampling angle, but not $C_{\mathrm{si}}$. The initial permeability $k_{0}$ depends much on the sampling angle for the three clays which are relevant to the initial anisotropy of clays.

The results of this study clearly show the anisotropic oedometric consolidation behavior of natural clays. It is meaningful to determine the anisotropic parameters associated with oedometric consolidation and use them for engineering designs and projects on clays. The perspectives of this study are now to relate 
these behaviors at the specimen size to microstructural analyses in order to better understand the physical origins of the material anisotropy.

\section{References}

Berry, P.L., Poskitt, T.J., 1972. The consolidation of peat. Géotechnique, 22(1):27-52. [doi:10.1680/geot.1972.22.1. 27]

Chen, Y.M., Tang, X.W., Jia, N., 2007. Consolidation of sensitive clay with vertical drain. International Journal for Numerical and Analytical Methods in Geomechanics, 31(15):1695-1713. [doi:10.1002/nag.620]

Casagrande, A., 1936. The Determination of the Preconsolidation Load and Its Practical Significance. Proceedings of 1st International Conference Soil Mechanics and Foundation Engineering, p.60-64.

Chinese Industry Standard, 1999. SL237-1999, Specification of Soil Test. The Ministry of Water Resources of the People's Republic of China.

Clayton, C.R., Simons, N.E., Matthews, M.C., 1982. Site Investigation. Blackwell Science, Oxford.

Duan, Y.Y., Zhang, Y.P., Chan, D., Yu, Y.N., 2012. Theoretical elastoplastic analysis for foundations with geosyntheticencased columns. Journal of Zhejiang UniversitySCIENCE A (Applied Physics \& Engineering), 13(7): 506-518. [doi:10.1631/jzus.A1100334]

Feng, T.W., 2010. Some observations on the oedometric consolidation strain rate behaviors of saturated clay. Journal of Geoengineering, 5(1):1-7.

Huang, M.S., Liu, Y.H., 2011. Simulation of yield characteristics and principal stress rotation effects of natural soft clay. Chinese Journal of Geotechnical Engineering, 33(11):1167-1175 (in Chinese).

Karstunen, M., Yin, Z.Y., 2010. Modelling time-dependent behaviour of Murro test embankment. Géotechnique, 60(10):735-749. [doi:10.1680/geot.8.P.027]

Lade, P.V., Kirkgard, M.M., 2000. Effects of stress rotation and changes of $b$-values on cross-anisotropic behaviour of natural, $K_{0}$-consolidated soft clay. Soils and Foundations, 40(6):93-105. [doi:10.3208/sandf.40.6_93]

Leoni, M., Karstunen, M., Vermeer, P.A., 2008. Anisotropic creep model for soft soils. Géotechnique, 58(3):215-226. [doi:10.1680/geot.2008.58.3.215]

Li, J.Z., Peng, F.L., Xu, L.S., 2009. One-dimensional viscous behavior of clay and its constitutive modeling. International Journal of Geomechanics, 9(2):43-51. [doi:10. 1061/(ASCE)1532-3641(2009)9:2(43)]

Li, Q., Ng, C.W.W., Liu, G.B., 2012. Low secondary compressibility and shear strength of Shanghai Clay. Journal of Central South University, 19(8):2323-2332. [doi:10. 1007/s11771-012-1278-9]

Li, Y.Q., Zhou, J., Xie, K.H., 2008. Environmental effects induced by excavation. Journal of Zhejiang UniversitySCIENCE A, 9(1):50-57. [doi:10.1631/jzus.A061434]

Mesri, G., Godlewski, P.M., 1977. Time and stress- compressibility interrelationship. Journal of the Geotechnical Engineering Division, 103(5):417-430.

Mesri, G., Castro, A., 1987. $C_{\alpha} / C_{\mathrm{c}}$ concept and $K_{0}$ during secondary compression. Journal of Geotechnical Engineering, 113(3):230-247. [doi:10.1061/(ASCE)0733-9410 (1987)113:3(230)]

Miao, L., Zhang, J., Wang, F., Houston, S.L., 2008. Timedependent deformation behavior of Jiangsu marine clay. Marine Georesources \& Geotechnology, 26(2):86-100. [doi:10.1080/10641190801952394]

O'Kelly, B.C., 2006. Compression and consolidation anisotropy of some soft soils. Geotechnical and Geological Engineering, 24(6):1715-1728. [doi:10.1007/s10706005-5760-0]

Shen, Y., Zhou, J., Gong, X.N., Liu, H.L., 2008. Study on Strength Criterion of Intact Soft Clay after Monotonic Principal Stress Rotation. Geotechnical Engineering for Disaster Mitigation and Rehabilitation. Springer Berlin Heidelberg, Berlin, p.892-898. [doi:10.1007/978-3-54079846-0_117]

Suneel, M., Park, L.K., Im, J.C., 2008. Compressibility characteristics of Korean marine clay. Marine Georesources \& Geotechnology, 26(2):111-127. [doi:10.1080/1064 1190802022478]

Wang, L.Z., Yin, Z.Y., 2012. Stress-dilatancy of natural soft clay under undrained creep condition. International Journal of Geomechanics, in press. [doi:10.1061/(ASCE) GM.1943-5622.0000271]

Wang, L.Z., Shen, K.L., Ye, S.H., 2008. Undrained shear strength of $K_{0}$ consolidated soft soils. International Journal of Geomechanics, 8(2):105-113. [doi:10.1061/ (ASCE)1532-3641(2008)8:2(105)]

Wang, L.Z., Wang, Z., Li, L.L., Wang, J.C., 2011. Construction behavior simulation of a hydraulic tunnel during standpipe lifting. Tunnelling and Underground Space Technology, 26(6):674-685. [doi:10.1016/j.tust.2011.05.009]

Wang, L.Z., Dan, H.B., Li, L.L., 2012. Modeling strain-rate dependent behavior of $K R_{0}$-consolidated soft clays. Journal of Engineering Mechanics, 138(7):738-748. [doi:10.1061/(ASCE)EM.1943-7889.0000371]

Yin, Z.Y., Hicher, P.Y., 2008. Identifying parameters controlling soil delayed behaviour from laboratory and in situ pressuremeter testing. International Journal for $\mathrm{Nu}$ merical and Analytical Methods in Geomechanics, 32(12): 1515-1535. [doi:10.1002/nag.684]

Yin, Z.Y., Chang, C.S., 2009a. Microstructural modelling of stress-dependent behaviour of clay. International Journal of Solids and Structures, 46(6):1373-1388. [doi:10.1016/ j.ijsolstr.2008.11.006]

Yin, Z.Y., Chang, C.S., 2009b. Non-uniqueness of critical state line in compression and extension conditions. International Journal for Numerical and Analytical Methods in Geomechanics, 33(10):1315-1338. [doi:10.1002/nag.770]

Yin, Z.Y., Chang, C.S., Hicher, P.Y., Karstunen, M., 2009. Micromechanical analysis of kinematic hardening in natural clay. International Journal of Plasticity, 25(8): 
1413-1435. [doi:10.1016/j.ijplas.2008.11.009]

Yin, Z.Y., Chang, C.S., Karstunen, M., Hicher, P.Y., 2010. An anisotropic elastic-viscoplastic model for soft clays. International Journal of Solids and Structures, 47(5): 665-677. [doi:10.1016/j.ijsolstr.2009.11.004]

Yin, Z.Y., Hattab, M., Hicher, P.Y., 2011. Multiscale modeling of a sensitive marine clay. International Journal for Numerical and Analytical Methods in Geomechanics, 35(15):1682-1702. [doi:10.1002/nag.977]

Yin, Z.Y., Xu, Q., Yu, C., 2013. Elastic viscoplastic modeling for natural soft clays considering nonlinear creep.
International Journal of Geomechanics, in press. [doi:10. 1061/(ASCE)GM.1943-5622.0000284]

Zeng, L.L., Hong, Z.S., Cai, Y.Q., Han, J., 2011. Change of hydraulic conductivity during compression of undisturbed and remolded clays. Applied Clay Science, 51(1-2):86-93. [doi:10.1016/j.clay.2010.11.005]

Zhang, Z.M., 2011. Achievements and problems of geotechnical engineering investigation in China. Journal of Zhejiang University-SCIENCE A (Applied Physics \& Engineering, 12(2):87-102. [doi:10.1631/jzus.A1000433] 